\title{
THE MEDICAL APPROACH TO THE RESETTLEMENT OF THE DISABLED
}

\author{
By F, S. COOKSEY, O.B.E., M.D., M.R.C.P.
}

Director, Department of Physical Medicine-King's College Hospital; Consultant Adviser in Physical Medicine to the Ministry of Health.

(INTERNATIONAL CONGRESS LECTURE).

$\mathbf{I}_{\mathrm{r}}^{\mathrm{T}}$ is an axiom of medical teaching that the doctor's responsibility does not end until a sick or injured patient has resumed his normal place in the community; or, in the case of permanent disability, until. he has been resettled in the most suitable conditions. Even so doctors are often criticized for showing too little interest in rehabilitation and even less interest in resettlement. There are reasons for this apparent contradiction between principle and practice which must be taken into account when considering the medical approach to resettlement.

In medical education emphasis is laid on the paramount importance of accurate diagnosis, of finding the cause of illness and the means of preventing it. Treatment, which seems so important in the presence of sickness, is, nevertheless, a necessity only until a disorder can be prevented; whilst resettlement applies only to a minority of cases in which treatment has failed to enable patients to return to their normal way of life. Thus the natural trend of medical interest is towards the acute stage of illness, and resettlement is apt to be regarded as a specialized procedure to be considered only when the doctor has failed in his primary, objective.

Another factor is that the doctor has around him the nurses, physical therapists, laboratory facilities, surgical instruments and drugs which he needs for the treatment of illness, and he is personally responsible for directing the use of these agents. Whereas, although the doctor is expected to advise on the medical aspects of resettlement and his certificate may be an essential preliminary to action, he is not so directly concerned with the management of these services. Indeed, he may have very little say in resettlement beyond making a recommendation, which may or may not be acted upon by people he seldom, if ever, meets.

The facilities for social and industrial welfare, including resettlement after illness, which have been developed in recent years are now so elaborate that it may well be asked if it is still practicable for doctors; who are already overtaxed by the urgency and complexity of purely medical matters, to assume much, if any, responsibility for resettlement. The answer is that medical responsibility cannot be avoided because treatment must be related to the type of life to which the patient will be returning, and those concerned with the resettlement services are dependent upon medical advice as to what conditions are suitable for a particular mental or physical disavility.

By way of examples, the stresses and strains of life play a major part in the aetiology of peptic ulceration and it is recognized that successful treatment depends as much on knowing how such conditions can be avoided as upon medical or surgical procedures. Again, lifting strains must be restricted or avoided after prolapse of an intervertebral disk, and only a doctor cah assess the extent of the weakness in the individual and decide if a particular type of work is likely or not to be harmful. Likewise, the physical effort permissible in heart disease requires reassessment from time to time because the cardiac condition is liable to change and usually for the worse. Similarly in other unstable conditions, such as tuberculosis and arthritis, medical advice about living conditions may be more effective than drugs. On the other hand, in stable conditions, such as poliomyelitis, medical guidance during resettlement is less important; but, as in most disorders, treatment at an earlier stage must be related to future activity. For instance, it may be necessary to arthrodese a flail wrist joint and for the majority of people fixation midway between pronation and supination is the most useful position; but a typist will not be able to resume her work unless the wrist is fixed in full pronation.

Countless examples, equally convincing, can be found in every branch of medicine. The conclusion must be that resettlement is an essential and integral part of medical practice; but the doctor's attention is being constantly diverted to the more urgent problems of acute illness, and his opportunity to apply his interest in resettlement is restricted because the necessary facilities are usually remote from his own practice and he has little direct responsibility for their operation. Therefore, the practical problem is how to make it easier for the doctor to apply his natural and essential interest in resettlement.

Somewhat similar problems confront physical therapists. Naturally their first concern is that the treatment they administer will lead to full recovery and that they will be given the opportunity to treat cases so early that they can virtually prevent disability. At the same time they are interested in the problems of resettlement, but they have even less direct responsibility than the doctors. If there is any criticism of physical therapists it is perhaps that there is a tendency to keep patients on treatment too long in the attempt to achieve a complete cure in the anatomical and physiological sense when it might be more praticable and economical to be content with a fair functional result and to get the patient back to work without unnecessary delay.

For instance, it is satisfying to obtain full movement in a stiff shoulder or knee after injury; but few people need full abduction of the shoulder or more than $90^{\circ}$ of knee flexion for their work and everyday activities. A useful functional range of movement is often obtained relatively quickly, but the last few degrees of abduction or flexion may take months. At the same time it is not uncommon to find that patients who were discharged with some limitation have recovered full movements spontaneously months or perhaps years later. Thus it is just as important to know when' to stop treatment and get on with resettlement as it is to recognize when treatment is indicated.

Another aspect is seen in the management of hemiplegia. The first aim of treatment is full recovery in the affected limbs, but experience shows that, whilst many patients regain the ability to walk fairly well, worthwhile recovery in the affected hand is the exception. In the long run it is more realistic to recognize that most cases are unlikely to regain useful function in the hand and to teach the 
patient how to live with the disability and how to make one hand do the work of two hands as far as possible.

It is difficult for physical therapists who are treating a disabled patient day after day to form an objective view of the case. This is no criticism of -physical therapists as such but an inevitable consequence of the nature of their work which brings them so close to the immediate problems, whereas the doctor has not only the advantage of reviewing the case at intervals but also of evaluating all the various methods of treatment for which he is primarily and ultimately responsible. Thus if physical therapists are to play the fullest part in rehabilitation and resettlement, ways must be found to enable them to obtain a more objective view of their work. This is best achieved through the technique of progress and resettlement case conferences, wherein they can make their observations along with their colleagues from other departments and then hear the medical summing-up of the case as a whole.

One of the most important things to find out is the size of the problem of resettlement. The Ministry of Labour have accurate figures in the industrial field. On the medical side less is known, but 'some indication can be obtained from a survey of a thousand consecutive patients discharged from the wards of King's College Hospital in the summer of 1950. 'This showed that nearly 75 per cent. of the patients were expected to make full recovery and return to their employment or, in the case of scholars, housewives, and those retired from work, to resume their normal. place in the community. A further 10 per cent. would resume their usual activities in spite of some permanent disability; 7 per cent. would suffer with chronic illness but be able to do their own work during remissions; and 4 per cent. were unfit for any work. Under. 1 per cent. would require resettlement in alternative work. in the immediate future; but it was assumed that some of the 7 per cent. chronic sick who might return to their work would require resettlement in more suitable work in due course. The remaining 3. per cent. were patients who were expected to die of cancer, heart disease and so on in the near future.

The figures are too small to draw conclusions, but the alarming feature is that apparently only 75 per cent. of patients passing through an acute hospital make full recovery. A further 17 per cent. with permanent disability or chronic illness can work but need the help of the rehabilitation and resettlement services to a greater or lesser extent. Even allowing for a wide margin of error in these figures it is clear that at least 10 per cent. of the patients passing through our acute hospital beds need help in their rehabilitation and resettlement, and this becomes a very big problem in terms of the total hospital population in the country.

On the whole, quite good progress has been made in this country in the development of facilities for medical rehabilitation, that is to say, the means to restore physical and mental function, but the provision for industrial resettlement is much better as you will hear from Mr. St. John Wilson. However, there is a gap which has not yet been satisfactorily bridged between the medical and industrial processes. The outstanding problems at the moment are, first, to make it possible for the doctor to develop and apply his interest in rehabilitation and resettlement. Secondly, to make it easier for physical therapists to see their work in wider perspective and, thirdly, to make certain that those concerned with industrial resettlement are consulted in good time and given all the medical guidance they need to enable them to make their maximum contribution to the welfare of disabled people.

Since the Disabled Persons Employment Act came into operation in 1944 the Ministry of Labour have wisely arranged that the Disablement Resettlement Officers at the employment exchanges should attend the hospitals to discuss the industrial resettlement of all disabled persons with the almoners and the members of the medical staff concerned. Unfortunately the medical profession have not shown much willingness to make use of this opportunity, and too often the almoner and D.R.O. have been at a disadvantage because of the lack of all important medica guidance. Furthermore, there is no provision for physiotherapists, occupational therapists and others who have got to know the patient's personality as well as his physical and mental capacity during treatment to contribute their view about the most suitable resettlement for the patient.

In recent years efforts to strengthen the link between the medical and industrial services have led to the development of the resettlement clinic or case conference in hospitals. The purpose is to provide expert medical social and vocational guidance during the latter stages of illness for patients who may require further rehabilitation and resettlement in suitable work after discharge from hospital.

The clinic is conducted by one of the medical staff interested in rehabilitation, and is attended by the almoner, physiotherapists, and occupational therapist, together with the D.R.O. from the local employment exchange and the patient. The patient's family doctor is invited to attend, but unfortunately time and distance often make this impracticable. Invitations are also extended to industrial medical officers, and other experts within and without the hospital when they are concerned with particular cases. By this means all the interested people are brought together. The usual procedure is for everyone to say what he knows and thinks about the case, and the best line of approach is agreed before the patient is brought in. The chairman then explains the position to the patient in simple terms and invites him to express his own views about the suggested course of action until finally a plan of action is agreed by all concerned. Of course, it is not possible to bring so many busy people together to discuss all resettlement problems, and these clinics only deal with the more interesting and difficult cases. The routine work continues to be done by direct contact between the almoner and D.R.O., but the clinic has the great advantage of stimulating interest in these problems in the medical, social and industrial field. All concerned learn more about each other's work and how to overcome the difficulties of administration and communication, which are not easy to avoid in such a complex procedure as rehabilitation and resettlement.

Our own experience at King's College Hospital has been that the resettlement clinic stimulates interest throughout the hospital. Members of the medical staff refer cases freely and some attend the clinic themselves whenever possible, thereby demonstrating that if the necessary facilities are established, and readily available, doctors will apply themselves to the problems of resettlement. The physical therapists welcome the opportunity to express their opinion about a difficult case, and I believe it helps them to get more out of their own work. The D.R.O. has not only the advantage of thorough briefing about the medical aspects before he starts on a case but he can also bring his own problem cases from the employment exchange back for review of the medical aspects when he feels this may be necessary.

There is little doubt that the establishment of resettlement clinics in all the major hospitals would help more than anything else towards bridging the vital gap between medical rehabilitation and industrial resettlement. 